\title{
Portelli, Alessandro (2020). Lluvia y veneno. Bob Dylan y una balada entre la tradición y la modernidad. Buenos Aires: Prometeo, 180 pp.
}

\author{
Gonzalo Pérez Álvarez \\ gperezalvarez@gmail.com \\ CONICET / Instituto de Investigaciones Históricas y \\ Sociales. Universidad Nacional de la Patagonia Sede \\ Trelew, Argentina

\section{Mónica Gatica} \\ monicagracielagatica@yahoo.com.ar \\ Instituto de Investigaciones Históricas y Sociales. \\ Universidad Nacional de la Patagonia Sede Trelew, \\ Argentina
}

Cita sugerida: Pérez Álvarez, G. y Gatica, M. (2021).

[Revisión del libro Lluvia y veneno. Bob Dylan y una balada entre la tradición y la modernidad por A. Portelli]. Aletheia, 11(22), e096. https://doi.org/10.24215/18533701e096 


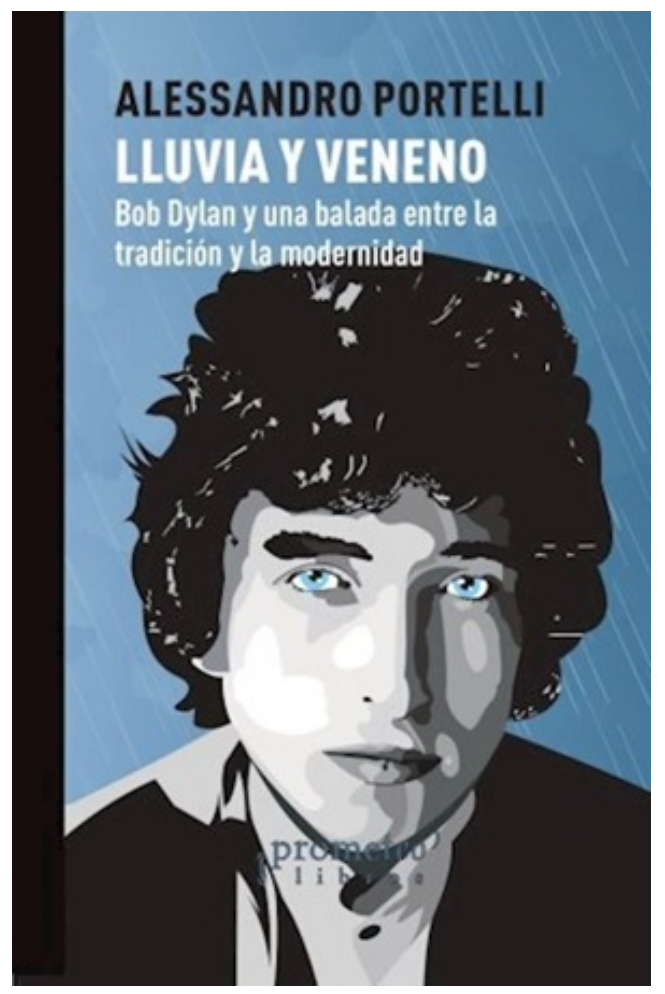

Un colega de nuestra Universidad Nacional de la Patagonia, el Mg. Pablo Blanco, nos compartió una idea: "Cuando Dylan muera habrá terminado el siglo XX". Proponía una periodización a partir de una figura, aparentemente "apenas" un individuo, pero que para ser comprendido requería analizar la totalidad de determinaciones que lo conformaron. Sabemos que el gran historiador Eric Hobsbawm sostuvo que el siglo XX terminó hacia 1989, con la caída del muro de Berlín y el derrumbe del proyecto soviético: el derribo del sueño revolucionario culminaba aquel siglo de guerras y rebeliones.

$\mathrm{Si}$, en cambio, fuese Dylan el factor de cierre, aquel "corto siglo XX" se transformaría en un "largo siglo", que incluiría la derrota revolucionaria y la extensa tristeza de los años ordenados en torno a esa "Melancolía de Izquierda”, a la que se refería Enzo Traverso. Portelli nos muestra que Dylan aún canta, que los destellos de las revoluciones derrotadas, de los desencantos y las traiciones, aún viven. Y que la lluvia que lave tanta sangre, y que prepare la tierra para una nueva siembra, aún no ha caído, o que, quizás, aún no ha terminado de caer... Aún no cae esa lluvia que, tal vez, nos salvará. O quizás aún sigue cayendo esa lluvia maldita, de la que el virus sea su versión más reciente.

Portelli construye, a través de una biografía, un recorrido apasionante por la historia americana y mundial del último "largo" medio siglo. Recorre casi la totalidad de los grandes problemas de la historia oral, y evidencia, sin buscarlo, su formación erudita sobre la historia oral y la cultura norteamericana. Esto expresa el grado de conocimiento que debe construir quien hace historia oral acerca de aquello que pretende comprender. Así como Gramsci nos decía que la historia de un partido debía constituirse en la historia de la totalidad nacional, Portelli, con la excusa de construir la historia de un cantautor o de una canción, cimienta una historia global.

Son uno y cientos de Dylan. Es el revolucionario y el vendido. El traidor y el héroe... Es el sueño revolucionario y el despertar en la derrota. $Y$ es mostrar que cerrar una fase, histórica o personal, no significa negarla, sino ir más allá. Dylan es muchos, y sus recuperaciones son también múltiples. Y contradictorias, sin que lo contradictorio sea mala palabra.

El autor nos invita a pensar en los hilos subterráneos de las culturas populares, esos vínculos que ligan a las clases subalternas, y su relación (de lucha, conflicto y complementariedad) con la cultura hegemónica... La producción de Dylan, su poesía o, como dice Joaquín Sabina, sus canciones... ¿ Son cultura popular o hegemónica? ¿Haber recibido el premio Nobel modifica esa situación? Para Portelli esto es una 
reivindicación, un logro. ¿Es eso o es la cooptación definitiva de su obra en clave sistémica? Se trata de uno de los tantos debates que el libro deja abierto.

Otra dimensión es la pregunta sobre si los historiadores orales damos voz a alguien o recibimos testimonios y los elaboramos. Portelli postula a Dylan como el más excelso historiador oral. Dice el autor:

Dylan, como muchos otros, ha contribuido, como dicen, a 'dar voz' a los prisioneros, a los esclavos y a otras generaciones de gente oprimida, olvidada y marginada; no obstante, estas personas no eran 'mudas' en absoluto porque tenían voces propias, hablaban, cantaban y es de sus voces que Bob Dylan recibe la suya (p. 47).

Constantemente emergen los grandes problemas de la historia social. Los debates sobre la experiencia, ya sea en clave de Kosseleck o Thompson, se entrevén cuando Portelli nos muestra cómo estas expresiones culturales son experiencia, que siempre se expresa de modo concreto, historizado. La balada es experiencia, en el tiempo y el territorio:

La balada sólo vive mientras se canta. Dado que nadie puede cantarla exactamente como la oyó o cantarla dos veces de la misma manera, sino que cada uno debe recuperarla de las profundidades de la memoria y reinventarla de acuerdo con su propia visión del mundo, la balada es siempre la misma, pero nunca es igual: no es 'atemporal' o 'timeless' sino exactamente lo contrario, existe solo en el tiempo y evoluciona con la historia (p. 64).

La balada funciona al modo de síntesis de miles de memorias populares, síntesis contradictoria, de lucha y comunicación. Porque "así es, en efecto, como funciona la memoria: asociaciones espontáneas que revelan significados imprevistos en fragmentos de experiencia” (p. 155). La memoria sucede en el tiempo presente, de cara al futuro, y no hacia el pasado.

Emerge en el libro otro problema clásico de la historia oral: la relación entre lo oral y lo escrito. Así como traducir es traicionar, transcribir la oralidad también implica una forma de ineludible traición. ¿ Cómo transcribir los silencios, las risas, las lágrimas, las miradas? Sobre este problema el libro cuenta con uno de los fragmentos más bellos de la escritura de Portelli:

Tanto la oralidad como la escritura luchan contra el tiempo: en la oralidad para detenerlo y en la escritura para sacudir su inercia. Por lo tanto, la oralidad y la escritura establecen una relación doble y cruzada con la vida y la muerte: la voz niega la muerte con su movimiento y su vínculo indisoluble con el cuerpo, pero la evoca con su desaparición; la escritura convoca a la muerte con su inmovilidad, pero la niega con su permanencia (p. 69).

Esa tensión, irresoluble, entre vida y muerte, entre movimiento y permanencia, debe ser una matriz permanente de nuestras preocupaciones.

Otro eje que ordena la reflexión del autor es la relación entre memoria, historia y oralidad... Portelli repasa: “...las culturas orales tienen una ideología de la conservación precisamente porque no tienen forma de almacenar nada excepto la intangibilidad lábil de la memoria” (p. 40). Desarrolla un profundo recorrido sobre los cambios y continuidades, y las tradiciones como puerta de posible ingreso a las rupturas. Aquello que parece "estático", procesualmente puede emerger como artífice de la transformación:

La conservación se apoya sobre la práctica inevitable del cambio: los cantantes y narradores siempre afirman que narran y cantan como sus antepasados, pero, en realidad, no pueden evitar cambiarlas cada vez, reivindicando la tradición como permanencia y practicándola como proceso (p. 68).

Las baladas analizadas:

nos dicen que es imposible tomar partido entre la continuidad y el cambio: lo nuevo puede desgarrar la estabilidad de nuestro mundo, pero lo viejo puede destruir una novedad deseable. En otras palabras, aquellos que tienen razones para temer el futuro no necesariamente están satisfechos con el presente (p. 136).

El presente, como dimensión contingente, es un territorio prefigurativo del futuro, donde lo "viejo” puede transfigurarse en constructor de lo "nuevo": "La 'memoria de clase' del viejo orden se convierte, en ciertos momentos, en una herramienta de resistencia y supervivencia del nuevo orden” (p. 125). 
La balada aparece como una narrativa clásica, una descripción densa de lo sucedido, de las cosas como pasaron y pasan. La explicación no hace falta, es superflua: será el contexto experiencial concreto de quien la escucha, y del artista que la canta y de cómo la canta, lo que pueda generar la interpretación y la acción práctica que se derive de la misma. Hasta que esos cambios no se plasmen en la realidad, nos dice Portelli, en la balada el hombre seguirá asesinando a la mujer, simplemente porque "los hombres matan a las mujeres" (p. 84). La balada es así, "una sórdida crónica que se ha transformado en el arquetipo de una antigua y permanente violencia” (p. 84). Develarlo es parte de nuestra tarea, concreta, históricamente situada.

Podríamos continuar, pero los límites de una reseña no lo permiten: sólo decir que en el libro también se registran otros debates en torno a la clase, las migraciones, las movilidades, el género. En esta obra se entretejen e imbrican, de forma condensada y compleja, todos los tópicos clásicos de las investigaciones de Portelli. El autor, en la presentación realizada en octubre de 2020 para la FaHCE y la Asociación de Historia Oral, afirmó que esta obra es, en diversos sentidos, autobiográfica. Es un recorrido sobre parte de la biografía de Dylan, y una revisión de la propia trayectoria militante e historiográfica de Portelli, en la que se recupera la temporalidad en común de quienes comparten una misma generación, no solo en un sentido biológico sino también experiencial.

Se trata, así, de un libro que tras la imagen de recorrer la producción de Dylan, reconoce y piensa ejes y problemas clásicos de la historia oral y la historia social, del conjunto de la producción histórica e historiográfica de Portelli. Así lo explicita el autor, cuando sostiene que:

Las fuentes orales, como vehículo privilegiado o historia recordada, ya sea individualmente o en formas tradicionales compartidas, poseen de una forma intensificada el poder que Carlo Ginzburg reconoce en todos los textos narrativos del pasado histórico: bajo la superficie textual y la información explícita que pueden trasmitir, podemos discernir, incluso en contra o más allá de las intenciones y la conciencia de los narradores, los fragmentos y rastros de una verdad más profunda (pp. 123-4).

La obra nos convoca con terca persistencia a luchar para que caiga esa anhelada lluvia. Una lluvia que no será necesariamente salvación, sino también desafío, peligro, convocatoria a jugárnosla por entero en pos de otro futuro. Una lluvia fuerte que caerá sobre una tierra reseca, como suele suceder en nuestra Patagonia. Una lluvia que es, a un tiempo, redención y reconocimiento de tantas luchas derrotadas, pero también dureza y crueldad. Una lluvia que no distingue sobre quién cae, pero que viene a transformar las cosas, de raíz. 